\title{
Depression, Self-Regulation, and Intersubjectivity
}

\section{Matthew Ratcliffe}

\begin{abstract}
This paper addresses the phenomenological relationships between affect-regulation and interpersonal experience in psychiatric illness. I argue that a capacity for affect-regulation is inextricable from how one relates to specific individuals and to other people in general. To do so, I focus on a type of experience often associated with depression diagnoses, involving a sense of stasis and inescapability. I show how a feeling of being estranged from other people amounts, at the same time, to a sense of the world as bereft of certain kinds of significant possibility and, by implication, to what we might call an experience of diminished self. This, I suggest, can be interpreted in terms of what I call "existential feeling”. I further consider how one might seek to regulate and change one’s felt relationship with the world and other people, despite feeling cut off from others in general and having a pervasive sense that emotional change is impossible.
\end{abstract}

Keywords: affect-regulation; depression; existential feeling; interpersonal experience; possibility

\section{Introduction}

In this paper, I explore the relationships between (a) a pervasive, felt relationship with the world, which I call "existential feeling”, (b) how one relates to other people in general, and (c) the ability to regulate emotions and feelings. To do so, I turn to experiences of psychiatric illness. I focus specifically on a form of experience often associated with depression diagnoses, where the world as a whole appears bereft of the potential for positive change and one's predicament is thus experienced as unchangeable, inescapable. I show how this kind of experience can be understood in terms of existential feeling and ask how, if at all, one might draw upon conscious affect-regulation strategies in order to modify it. This might seem like an impossible task. If an alternative strikes one as utterly inconceivable, if one cannot even contemplate the possibility of things changing for the better, one will surely be incapable of seeking out positive change. However, the situation is not so clear-cut. First of all, I argue that a sense of the world as lacking certain kinds of possibility is inextricable from an experience of being estranged from other people in general. Alienation from certain kinds of interpersonal relation is, at the same time, a loss of self-transformative possibilities that more usually imbue one’s current situation with a 
sense of contingency. Then I emphasize a distinction between short-term and longer-term anticipatory processes involving other people, between experiencing them as offering certain kinds of possibility and anticipating such experiences beforehand. Even where one is unable to anticipate certain kinds of interpersonal experience, one might still retain something of the capacity for such experiences. Drawing on first-person testimonies, I go on explore some of the ways in which interpersonal processes might continue to shape and regulate existential feeling in depression. In so doing, I develop a phenomenological account of the relationship between affect-regulation and interpersonal experience that can inform our understanding of psychiatric illness more generally, with potential implications for treatment.

\section{Depression and Existential Feeling}

A depression diagnosis is compatible with various different kinds of experience, even if we restrict ourselves to categories such as "major depression” (American Psychiatric Association, 2013) or "severe depression" (World Health Organization, 1992). Despite this diversity, a common theme in first-person accounts is that depression involves a profound and all-enveloping change in how one experiences and relates to the world and to other people. This is often described in terms of inhabiting a world quite different from one that was previously taken for granted, a world adrift from consensus reality. An associated theme is that escape from this world is impossible. It is not taken to be contingently true that one is unlikely to recover or will never recover. In more severe cases, one cannot contemplate any alternative to one's current predicament; the world offers nothing else. This is something that most published autobiographical accounts of depression explicitly remark upon. For example:

There was and could be no other life than the bleak shadowland I now inhabited. (Shaw, 1997, p.25)

In the middle of a depressive episode, it is impossible to believe it will pass. (Burnard, 2006, p.244) I am in a time-locked place, where the moment I am in will stretch on, agonizingly, forever. There is no possibility of redemption or hope. (Lott, 1996, pp.246-7)

It is the glass wall that separates us from life, from ourselves, that is so truly frightening in depression. It is a terrible sense of our own overwhelming reality, a reality that we know has nothing to do with the reality that we once knew. And from which we think we will never escape. (Brampton, 2008, p.171) 
Elsewhere, I have suggested that such experiences can be understood in terms of "existential feeling” (Ratcliffe, 2005; 2008; 2015). Existential feelings are distinct from emotions and moods, at least where the latter are conceived of as intentional attitudes with variably specific contents, such as "I am angry with the British Government" or "I am in a very bad mood about Brexit”. When we have such experiences, we already find ourselves situated in a shared world. This presupposed sense of belonging to a world is itself susceptible to changes, which are sometimes subtle and sometimes more pronounced. Such changes are often expressed in terms of diffuse feelings of unfamiliarity, unreality, detachment, being lost, uprooted, or adrift. Others involve feelings of belonging, safety, being at home in the world, being part of things, and so forth.

To further clarify the nature of existential feeling, I have offered an analysis according to which these feelings consist in a sense of the kinds of possibility that the experienced world incorporates. For instance, for an entity to appear threatening or practically enticing, one must be receptive to the relevant types of possibility: threat and practical enticement. Our sense of being rooted in a world centrally involves being open to a range of significant possibilities like these. We inhabit a realm where it is possible to be threatened and, conversely, possible to be drawn in by things in positive ways. Changes in existential feeling are changes in the kinds of possibility we are open to. Hence our openness or lack of openness to types of possibility is integral to experience, as opposed to being a non-phenomenological disposition to have one or another kind of experience. Existential feelings, I have further argued, are inextricable from felt bodily dispositions. It is through our feeling bodies that we experience things as mattering in various ways. For instance, the experience of something as immediately threatening in a physical way is at the same time a felt disposition to retreat from it, to avoid it, to shield oneself from it, or to hide. Existential feelings therefore have an essentially bodily phenomenology; they involve a felt appreciation of the kinds of possibilities on offer.

Drawing on this analysis, I have argued that types of experience associated with the label “depression” involve lack of access to certain kinds of significant possibility, a lack that is itself felt (Ratcliffe, 2015). The world appears as bereft of possibility. The apparent inescapability of depression can be understood in this way. More usually, our experience of a given situation includes possibilities for various kinds of significant change. Importantly, an appreciation of 
one's situation as contingent, as escapable, is constituted by a sense of its being susceptible to these changes. Central to the sense of contingency, but not exhaustive of it, are possibilities that involve things changing for the better in some way. For example, insofar as things appear practically significant in the context of a goal-directed project, a current situation calls out to us for improvement, thus presupposing the possibility of things improving. This is something the world of depression lacks. A current situation no longer offers the prospect of positive change. One's surroundings appear bereft of the relevant possibilities, and one cannot imagine them either. Consequently, one cannot entertain the possibility of things ever getting better or, more specifically, of recovering from depression. One can still utter "I will recover" or "the world will not always be like this", but these utterances are experienced as hollow, devoid of genuine conviction. They do not suffice to override a sense of the world as wholly bereft of the types of possibility required for the potential truth of such propositions.

Granted, the loss of possibility is not always so extreme. It comes in varying degrees. Furthermore, certain types of positive change may be absent from the world while others remain. Many first-person accounts of depression also emphasize how other types of significant possibility can remain, becoming more salient or even all-enveloping in the absence of positive change. For instance, the world as a whole might present itself in the guise of an inchoate threat, the arrival of which seems ever-immanent. So there are many importantly different predicaments to be discerned here. Nevertheless, a sense of stasis, inescapability, and impossibility is common to many of them and, in all cases, this can be interpreted in terms of diminished or absent access to types of possibility. It is this aspect of depression-experience that I will focus on here, rather than attempting to do justice to the wider phenomenology, its dynamics, and its interpersonal diversity.

Loss of significant possibilities from the world also amounts to a more general alteration of experience. It is, at the same time, a change in how one's body and one's agency are experienced. When one is no longer drawn in by one's surroundings, one's body appears curiously disengaged, conspicuous. And, in a world bereft of meaningful possibilities, of kinds that one might seek to actualize, purposive actions seem not merely difficult but impossible. Without the prospect of meaningful transition from a current situation to an anticipated situation, the sense of time is altered too. The world is curiously static, devoid of certain kinds of transition. The overall predicament is sometimes conveyed in terms of the diminishment, loss, 
non-existence, or death of "self”. For example, “I had the painful sensation that I was dead, or worse, had never been born...I didn’t exist, so I could take no pleasure in the material world....I felt like I'd been found incompetent and fired from my own life” (Steinke, 2001, p.64). When an ordinarily presupposed sense of experiencing and being able to engage with a significant, changeable world is eroded, one is no longer a locus of experience in quite the way one was. One’s perspective is impoverished; it ceases to accommodate kinds of experienced and imagined possibility, kinds of practical access, and kinds of temporal transition. Hence the capacity for certain types of intentional experience is diminished or absent, such as that of "encountering something as significant in manner $x$ or manner $y$ ” and that of hoping for something. All of this is experienced as a kind of self-diminishment. ${ }^{1}$

In what follows, I will address the question of how this experience of selfdiminishment and loss of possibility from the world relates to a sense of isolation from other people. In particular, I will show how loss of access to interpersonal affect-regulation processes is inseparable from a wider sense of the world as static and lacking. I will also consider how, if at all, one might consciously regulate existential feeling, in a case where the relevant feeling interferes with an ability to contemplate positive change. Although I refer specifically to “depression”, I do not wish to suggest that such experiences are exclusive to depression or that all depression-experiences are similar in kind. As I have argued elsewhere, labels such as “major depression” accommodate considerable phenomenological diversity. In addition, it is not always clear where or how to draw the line between depression and other diagnoses (Ratcliffe, 2015). Hence what I am referring to here is a broad kind of experience, often but not always associated with a diagnosis of depression.

\section{Affect-Regulation}

Although there are many different theories of "emotion”, almost all of them agree that emotion or emotional feeling is inextricable from an appreciation of our surroundings as salient and in

\footnotetext{
${ }^{1}$ I would therefore argue that many depression-experiences involve the erosion and distortion of what has been referred to as "minimal self": a sense of being a singular locus of experience. This is characterized as something integral to all of our experiences, which is to be distinguished from a pre-reflective or reflective object of experience, and also from a separate subject of experience (Zahavi, 2014). Others have argued that disruption of minimal self is specific to schizophrenia (e.g. Parnas et al., 2005). However, I am inclined to maintain that diminishment of self-experience occurs in depression as well, and certainly in more severe cases, but that it is qualitatively different and perhaps less profound than kinds of self-disturbance sometimes associated with certain other psychiatric diagnoses (Ratcliffe, 2015; 2017).
} 
one or another way significant. Existential feelings, I have argued, are limits on the kinds of significant possibilities that a person is open to and, by implication, on the kinds of emotions she can experience. It follows that existential feelings constrain the capacity for emotion-regulation or, at least, for kinds of emotion regulation that are not entirely non-conscious. Given this, I want to consider two issues: (a) whether we can also regulate emotions by changing existential feelings and, in so doing, changing our emotional repertoire; (b) whether some capacity to do so remains in cases where an existential feeling presents itself as inescapable, irrevocable.

How should we think of emotion-regulation more generally? Gross (1999; 2001) notes that emotions are not single, episodic mental events but multi-faceted processes that are susceptible to many different kinds of intervention. He distinguishes between two broad types of strategy, "antecedent-focused" and "response-focused", where the former involve intervening in an emotional process early on, while the latter involve altering it when it is well underway. Antecedent-focused strategies include "situation selection”, “situation modification”, “attentional deployment”, and "cognitive change” (a change in how the relevant situation is construed or appraised), while response-focused strategies involve "response modulation” (and, in particular, suppression of emotional responses). According to Gross (2001), suppression is ineffective compared to reappraisal, as it tends not to eradicate various somatic components of the emotion. Gross further distinguishes between conscious and non-conscious emotion regulation, and between regulation of emotion and regulation by emotion. The term “emotion-regulation”, he suggests, is better applied specifically to cases where emotions are themselves the objects of regulatory processes than to a wider range of cases where emotions are somehow implicated in regulatory processes.

I am specifically concerned with the phenomenologically accessible aspects of emotion regulation (and with the regulation of conscious "feeling” or "affect”, construed more broadly). This includes both (a) acting in order to regulate emotion and (b) acting in order to accomplish something else, which also happens to change one's emotional state and could not be accomplished (or, at least, experienced as accomplished) without the associated emotional change. In (a), the emotion is itself an explicit object of concern, and a person may have varying degrees of insight into what she is trying to do and why. In (b), she does not explicitly seek to manipulate her emotions and may have a complete lack of insight into how they are influenced by her activities. We can add that the line between conscious and non-conscious processes is far 
from clear-cut, especially in (b). One could shape and re-shape one's emotions in reliable ways by acting on $x$, which changes emotion $y$, where one knowingly acts on $x$ but the processes linking $x$ and $y$ are largely or wholly nonconscious. Furthermore, one might lack reflective, articulate knowledge that there exists a causal relationship or even a correlation between $x$ and $y$. A straightforward example would be going for a run every morning in order to keep fit or enjoy one's surroundings, while unknowingly relying on the routine (and on associated neurobiological processes) to sustain or enhance a longer-term feeling of well-being. I am concerned principally with cases where a person is explicitly pre-occupied with the prospect of emotional change, whether or not she takes it to be possible or achievable. Perhaps these are comparatively uncommon in everyday life, but they are more common in psychiatric illness, where people often seek relief from recalcitrant and unpleasant feelings. That said, the line between intentionally acting on one's emotions and doing so by acting on something else remains blurred. Moreover, there are varying degrees of insight into what one is doing. Consciously doing $p$ need not add up to reflectively taking oneself to be consciously doing $p$. There can also be tensions between what one takes oneself to be doing and the actual effects of one's activities on experience.

Existential feelings, it has been suggested, pose a particular problem for affect-regulation. Achim Stephan (2012, p.159) describes this as follows:

Although, for many persons, it already seems to be a difficult task to regulate (dysfunctional) emotions, the challenge is even more demanding when (harmful) existential feelings are at issue. Reasons for the recalcitrance of existential feelings are their background character, and the special type of intentionality they have, that is, their nonspecificity towards particular situations and events.

I do not think this problem extends to existential feelings more generally. More usually, they involve experiencing one's current situation as contingent, as potentially changeable in significant ways. Existential feelings thus include, by implication, some sense of their own contingency and fragility. So, although our experiences and activities are constrained by existential feeling, these constraints do not imply an inability to contemplate "existential change”. To put it cryptically, one can be experientially open to the possibility of possibilities that one is not currently open to. In other words, the possibilities sewn into the experienced world include self-transformative possibilities. This sense of contingency allows for the 
conscious employment of various different antecedent- and response-focused strategies. I am not suggesting that, in the usual case, one explicitly sets out to change existential feeling; one need not have reflective insight into this aspect of experience. The point is that one is open to the possibility of existential change, even if it is not conceived of as such.

However, the world of depression clearly does pose a problem for existential feeling regulation: how can we consciously manipulate existential feelings that themselves prevent us from contemplating the possibility of meaningful change? Here, all of Stephan's concerns apply. For Gross (2001), the strategy of "reappraisal” is an important one. As we will see, depression does accommodate various possibilities for reappraisal. Even so, one cannot overthrow -in an explicit, propositional way- the overarching conviction that escape is impossible, that one cannot recover, that there is no hope. This is because one's world does not incorporate the types of possibility needed for reappraisal. Neither, it seems, can "situation selection” or "situation modification” do the job. Granted, that a predicament seems irrevocable does not imply that it is. And, in many cases of depression, situational changes no doubt do influence existential feeling. But what is lacking in more severe cases is a sense that a change of situation could have such effects. Hence it is unclear how situational change could be part of a conscious attempt to alter that situation for the better.

How might this sense of impossibility, this inability to think outside of one's feeling, be circumvented? One could act on the existential feeling indirectly, at least where there remains some sense that certain kinds of significant change are possible. Hence, while one might not be able to contemplate escaping from the world of depression, one might consider doing $p$, which then opens up the possibility of $q$, and so forth. For instance, one might seek to distract oneself from unpleasant thoughts that the feeling disposes one towards, by engaging in one or another form of activity, and end up altering the underlying feeling in the process. A strategy that Stephan (2012, p.160) regards as promising is attentional redeployment. One can, he suggests, teach oneself to attend to aspects of life that are "at the heart of one's whole situation and feelings of being”. These can then be reappraised, thus indirectly influencing existential feelings that are somehow fueled by the original appraisals. Again, though, there is the worry that the prospects for reappraisal are constrained by existential feeling. One cannot always reshape an existential feeling by reappraising a current or past situation, given that the situation, even if it 
somehow caused the relevant existential feeling, is now appraised through that feeling. So the kinds of possibility needed for effective reappraisal may be inaccessible.

However, there is something else that Stephan does not consider: the interpersonal. I want to suggest that an emphasis on interpersonal regulatory processes is essential to understanding the world of depression. Furthermore, interpersonal processes can play important roles in altering the world of depression, whether this involves re-instilling a sense of contingency or further enforcing a feeling of inescapability. Gross (1999; 2001) distinguishes regulating one's own emotions from regulating the emotions of others, and concentrates largely on the former. However, it is important to acknowledge the extent to which self-regulation is reliant on interpersonal processes. Indeed, where humans are concerned, it is questionable whether the two should be treated as distinct. For example, Diamond and Aspinwall (2003, p.146) suggest that the boundary between self- and other-based regulation is "relatively fluid" and that there are grounds for taking the "dyad" rather than the individual as a unit of analysis. More generally, we might say that affect-regulation is environmentally embedded or, if you prefer, reliant on environmental scaffolding. We regulate our emotions as we respond to salient features of the environment, but we also configure our surrounding environments so as to regulate our emotions. As noted by Colombetti and Krueger (2014, p.10), we manipulate and interact with features of the environment in consistent, patterned ways, which elicit and shape emotions in a manner that is sometimes shared and sometimes idiosyncratic. For instance, we might go to a church, cinema, or bar. Or we might listen to music, drink alcohol, or go for a run in the park. Importantly, other people also operate as emotion-regulators. Being open to someone in the right kind of self-affecting way involves a form of trust, something that is usually prereflective and habitual:

As with material resources, we trust some people more than others; and again, the sense of "trust" we have in mind here refers to the expectation that others will have a certain modulatory impact on our affective life. (Colombetti and Krueger, 2014, p.10)

To better understand the sense of impossibility common to many depression-experiences, and also to assess the prospects for existential feeling regulation in depression, it is important to appreciate exactly how world-experience and affect-regulation depend on relations with others. 


\section{Other People as Affect-Regulators}

The static world of depression is invariably associated with estrangement from others. Sometimes, the depressed person feels somehow distant from everyone, unable to connect, as though they reside elsewhere. Sometimes, she experiences others in general as hostile, untrustworthy, and/or uncaring. And, in other instances, guilt, shame, and/or self-hate are prominent, adding up to a sense of social exclusion. However, an overarching theme is that a type of interpersonal connection, which most people take for granted in the course of everyday life, no longer seems possible. This estrangement from others is absolutely central to the stasis of depression. And, it should be added, experiences of loneliness, isolation, and social exclusion are similarly central to psychiatric illness more generally (Ratcliffe, 2015; 2017).

So, how and why does a feeling of being cut-off from others impact on a wider ability to regulate experience, thought, and activity? More usually, mundane interactions with other people shape our experiences of salience and significance in all sorts of subtle ways that we seldom explicitly attend to. Consider the following passage:

I am walking in the forest with a friend. As we stroll we point out various things to one another: the color of the leaves, a passing bird, the changing of the seasons. I adjust to my friend's pace and she to mine. I find myself enjoying things more and in a different way than when I had come alone. We speak of other topics beside the scenery: of politics, mutual friends, movies each has seen. But then we lapse into silent enjoyment of our surroundings. (Leder, 1990, p.94)

Who we are with and how we relate them can influence our experience of a shared situation in various different ways. A comfortable, effortless, interesting conversation with a friend, had while walking through a place of mutual interest, might enhance the salience of certain things, making them appear significant in ways they would not have done had one been alone. In contrast, a long, uncomfortable, obligatory dinner with someone, characterized by mutual awkwardness and an absence of fluid expressive and gestural interaction, can suck the life out of one's surroundings, making a restaurant that might otherwise have seemed warm and welcoming appear decidedly uncomfortable.

Casual observations such as these are consistent with numerous empirical findings, all of which indicate that being in the presence of another person and interacting with her influences, in 
a pre-reflective way, what appears salient, the kind of significance it has, what seems achievable, and which actions present themselves as situationally appropriate (e.g. Bayliss et al., 2007; Sebanz, Bekkering, and Knoblich, 2006; Sebanz and Knoblich, 2009; Becchio, Bertone, and Castiello, 2008). ${ }^{2}$

However, I want to go further than this. The claim that other people influence what we take to be salient and significant needs to be distinguished from two stronger claims: (i) we experience people as having the potential to shape what matters to us and how, even if we do not explicitly conceptualize the relevant experience in that way; (ii) to experience someone in a distinctively personal way is, amongst other things, to experience her as a locus of potentially self-transformative possibilities. I endorse both claims. When we see an entity such as a hammer, it is often experienced as offering quite specific possibilities in the context of a project. The same applies to artefacts more generally. But other people are importantly different. While a person might similarly present the possibility of assisting in task $x$, she also offers the possibility of interactions that promise to alter one's sense of the possibilities on offer. For the most part, this aspect of interpersonal experience is pre-reflective. We do not explicitly think of other people as loci of self-transformative possibilities. However, there are varying degrees of insight. We might phone a particular person in the knowledge that she has the ability to make us feel better, but without any clear sense of how she might achieve this. And it is commonplace to seek out a certain kind of interpersonal situation in order to shake oneself out of a recalcitrant, unpleasant emotional state and/or reappraise the significance of events and situations.

Other people thus inject a distinctive kind of contingency into the world. As Løgstrup (1956/1997, p.18) observes, we cannot avoid influencing each other in the relevant ways. Every encounter we have with another person has some effect on her "world”, however subtle it may be:

By our very attitude to one another we help to shape one another's world. By our attitude to the other person we help to determine the scope and hue of his or her world; we make it large or small, bright or drab, rich or dull, threatening or secure. We help to shape his or her world not by theories and views but by our very attitude toward him or her.

\footnotetext{
${ }^{2}$ Here, I am concerned exclusively with the relevant phenomenology. However, I acknowledge that there is an accompanying story to be told about the various neurobiological processes involved, how they operate, how they interact with each other, and how they interact with interpersonal processes.
} 
Being open to the influence of others, rendering oneself vulnerable to it, involves experiencing them as loci of potentially positive change, something that Løgstrup refers to as a basic form of "trust". But the world of depression is different. It may well retain the possibility of being affected by others in certain ways. But what is lacking is the possibility of their reshaping one's situation for the better, and of their doing so in ways that cannot be fully anticipated. More usually, others point to something more, to an open future that is consistent with the possibility of hope. The potential for kinds of transformative interaction is thus integral to the distinctiveness of personal experience. This potential includes ways of altering one's world (and, conversely, the other's world as well) that are specific to interactions with particular individuals, rather than generic. In more severe forms of depression, however, the prospect of selftransformative interpersonal encounters is diminished and may even be altogether lost. With this, a sense of others as persons is eroded. The kinds of interpersonal possibility that remain tend to be much more generic: 'they all hate me', 'they think I'm worthless'; 'they are not to be trusted'; 'I am not worthy in their eyes'. For example, where guilt is a central theme, others may appear only as indistinguishable instances of the type "judge":

He no longer perceived the personal and individual worth of men; for him they were only faint, disfigured silhouettes cut out of the general ground of hostility. In fact, he was not persecuted by living men but by men who were transformed into persecutors and were only that. He no longer saw the total, complex life of the human being. Men had become schematic manikins. (Minkowski, 1970, p.189)

We can now see why the closed world of depression is inextricable from changes in the interpersonal realm. When one is able to interact with and anticipate interacting with other people in a fully rich way, one's world cannot appear unchanging and inescapable. So the world of depression is not only contingently associated with pervasive estrangement from others; this estrangement is implied. And the dependence is mutual. A world bereft of certain types of interpersonal possibility cannot but appear closed and static. A full sense of one's current predicament as contingent does not just involve an openness to the concrete possibilities currently on offer, where these can be clearly specified (for instance, doing $p$ to achieve $q$ or to avoid $r$ ). Other possibilities remain inchoate and constitute the recognition that currently 
experienced patterns of significance and salience to not exhaust what the world has to offer. This openness and indeterminacy is to be identified with the prospect of types of interpersonal relation. Of course, one could argue that, even without these relations, certain possibilities for positive change can remain. And I accept that this is so. The person may still be able to appreciate that a situation where $p$ happens or where $p$ is done is somehow better than an alternative. Nevertheless, a wider sense of openness is lost. In addition, many of those possibilities that belong to familiar situations, such as pursuing a project with someone or doing something for someone, implicate other people in one or another way. If the required interpersonal relations are experienced as wholly inaccessible, these possibilities will be extinguished as well.

This approach serves to illuminate first-person descriptions of depression, which consistently describe profound and seemingly inescapable changes in how one experiences and relates to the world, while also indicating that these changes are closely associated with forms of estrangement from other people. Here are some representative accounts, taken from responses to a questionnaire study that I conducted with colleagues in 2011:

"I used to think that family and friends didn't care, that if they went to bed at night instead of staying up and checking I was OK or worrying about me then that meant that they didn't care at all. It felt like everyone was lying to me, like they were just telling me they loved me and cared to make me feel better. I felt like a huge burden on everyone.....Life seems completely pointless when depressed. Depression is the worst feeling in the world and when you're absorbed in its depths you just don't even want to be there, anything to stop the numbness and pain. You can't see far into the future so you can't see aspirations or dreams. Everything I ever wanted to do with my life before seemed impossible now. I also would think that I would never get out, that I'd be depressed forever. It brings quite irrational thinking because it's not a rational illness. It makes you think all sorts of things about life and yourself that aren't true. I thought I'd never escape from the depths of depression and never achieve anything with my life.” “The world looks very different when depressed as I find my life becomes valueless. The world seems very bleak and there seems to be no point in anything. All actions and tasks become pointless and irritating. Daily tasks become a chore and social contact becomes a real hassle. The problem with depression is you lose hope and then you get very self-destructive. I also find that the world becomes a dark and dangerous place and I become unable to find any joy or happiness in it..... find other people irritating when depressed. Especially those that have never suffered with 
depression and find the 'advice' often given by these is unempathetic and ridiculous. When depressed I find it hard to control emotions such as anger and irritability and find it easier to withdraw from social contact than to try and engage with people. Being with friends and family can become tiring and challenging.”

"When I am depressed the world looks hopeless and I am unable to see it getting better, I find myself dwelling on horrific world events and can only see the negative that goes on in life. I also blame myself for the bad things that do happen.....I am much quicker to irritate when I am depressed, I also only pick up on their negativity and assume it is directed towards me. I become paranoid that my friends and family hate me.... When depressed I feel I have no future and lose any hope in things improving in my life. I just feel generally hopeless.”

In emphasizing a sense that things cannot improve, along with a lack of connection with other people, these testimonies exemplify a theme that is common to almost all first-person accounts of depression. ${ }^{3}$ This does not imply a causal relationship between the world of depression and estrangement from others. Rather, I have suggested that the two are inseparable. Even so, their interdependence makes clear that, in addressing affect-regulation in depression, the role of interpersonal regulators (and their absence) needs be considered. ${ }^{4}$ In the remainder of this paper, I will address how a person might continue to regulate existential feeling when cutoff, to some degree, from interpersonal processes that more usually instill a sense of contingency. To do so, I will again draw on the 2011 questionnaire study. ${ }^{5}$ I do not treat these testimonies as representative or authoritative, and I do not seek to make confident generalizations. The aim is merely to offer a tentative sketch of types of regulative resource that people are sometimes still able to draw upon, even if they don't realize it.

When alienated from interpersonal processes, people may resort to various other ways of regulating emotion. These are sometimes ineffective, counterproductive, or otherwise harmful, as

\footnotetext{
${ }^{3}$ There were 145 complete responses to this study, most of which went into considerable detail. All of the respondents quoted in this paper had current or past diagnoses of one or another form of "depression" and, in some cases, other psychiatric diagnoses as well. I have corrected spelling mistakes and some grammatical errors, but not in a way that could alter the meaning. For a full account of the study, and a discussion of associated methodological issues, see Ratcliffe (2015, Chapter 1).

${ }^{4}$ It is also plausible to suggest that interpersonal and social processes frequently play a major role in causing psychiatric illness (Ratcliffe, 2017). For instance, what one anticipates from other people depends, to some extent, on a history of interaction, with specific others and with others in general. See Varga and Krueger (2013) for a complementary developmental perspective on depression and intersubjectivity.

${ }^{5}$ Unless otherwise indicated, quotations that appear in what follows are taken from questionnaire responses.
} 
with alcohol abuse and substance abuse more generally. Some people refer to self-harm as a deliberate attempt to self-regulate, to cope: "I self-injured for 3 years, by cutting my arms. Stopping self-injuring helped me overcome depression because it taught me to find alternative coping strategies and helped me learn to respect myself”. Something else that many people describe is reflecting on one's past deeds, passing judgment on oneself, and getting sucked into cycles of rumination that only make things worse:

"When I'm particularly depressed I tend to feel anxious, often isolated. I spend a lot of time denigrating and berating myself, often for what can be a simple mistake. This tends to cause more frustration, i.e. getting mad with myself for getting mad, and sets me off on a downward spiral. I then expend a lot of energy trying to control this, which makes me tired and irritable. I often feel hate and disgust towards myself - I can't see pictures of me without wanting to tear them up or poke my eyes out. Sometimes I feel this towards others as well.”

In at least some instances, rumination may constitute an attempt to re-appraise one’s predicament, but one that is inevitably unsuccessful, as one cannot summon up the required types of possibility. One is unable to disengage from patterns of thinking that confirm, again and again, interpretations that are consistent with the world of depression: "I can't think about anything positive just negative thoughts. I only think about my own problems and they keep going round and round my head with no let up and no escape”. That said, self-narratives can also play more positive regulatory roles. Construing one’s depression as something deserved is plausibly more likely to impede recovery than an interpretation that treats it as a misfortune: “There is a tremendous guilt for me in depression - I'm weak, not like others who cope, therefore it's my fault”. Something else that may well perpetuate or exacerbate a sense of estrangement and inescapability is physically cutting oneself off from others. Where anticipated interpersonal encounters present themselves as uncomfortable, devoid of the prospect of connection, or perhaps as offering only harm, shame, and humiliation, a person may try to cope by actively withdrawing from the social world, and thus retreating further from kinds of self-transformative interaction that might otherwise open up the possibility of escape: 
"I isolate myself a lot of the time, this is worse when I am feeling very depressed, in that way family and friends seem different to me. Although it is more my perception that they don't want to be bothered with me and have other things going on. It seems better to isolate myself from people.”

In conjunction with or instead of this, some people strive to hide their predicament from others, by preserving routines and keeping up appearances:

“I worked very hard to ensure that it didn't interfere with my routine - I didn't take any time off work, I tried to make it to the gym etc. but in some ways I think it would've been more sensible if I'd not tried so hard to pretend everything was 'normal'."

“As I said, because I am an expert at slipping on a mask and acting normally (whatever normal is) I am able to carry out routine tasks and everyday activities alright, even if inside I would rather be locked in my room or in bed all day with the covers over me and not venturing out at all or doing anything.”

Overall, it is unclear whether such performances tend to aid regulation or to further dysregulation. Perhaps they can help preserve something of a meaningful world. Then again, they plausibly exacerbate the sense that "nobody understands", "nobody can connect with me or my experience”.

Even so, none of this implies a complete lack of access to interpersonal regulation processes. More usually, other people influence our experiences of salience and significance in ways that we are not reflectively aware of, and the same point applies to depression. Importantly, an inability to contemplate having interpersonal interactions of a certain type is distinct from an inability to have such interactions. ${ }^{6}$ Hence we need to distinguish between an immediate and a longer-term sense of the possibilities offered by other people. While one might no longer anticipate experiencing certain possibilities in the context of interpersonal interactions, one might still be capable of experiencing some such possibilities. It may well be that some people really

\footnotetext{
${ }^{6}$ Similarly, a sense of one's predicament as inescapable and timeless does not imply that it is actually long-term or recalcitrant to change. Indeed, diagnoses of depression are often associated with emotional turbulence, involving rapid and extreme changes in emotion and mood. For instance, this is generally the case when depression is diagnosed in conjunction with borderline personality disorder. Here, I have chosen to focus on the experience of stasis. However, in studying the role of interpersonal emotion-regulation process, one could equally consider various forms of affective instability, emphasizing the contrasts between structured and situationally responsive emotional transitions, unstructured and intense emotional disturbances, and how the former involve interpersonal processes that are lacking in the latter.
} 
are utterly impervious to self-affecting processes of the relevant kinds. But, for others, the sense of impossibility is more sensitive to situational change than it seems to be. Even if a person cannot engage in interpersonal interaction with the explicit hope of altering existential feeling, she may be motivated to do so in other ways or be drawn into interactions elicited by others. These interactions may then have unanticipated effects, which themselves open up new possibilities. This points to complicated scenarios, where a person cannot contemplate $z$, but is able to do $p$ in order to achieve $q$, which opens up the possibility of $r$, which in turn renders him able to experience $s$, until we eventually get to $z$. Hence regulation of existential feeling need not begin with an explicit attempt to manipulate it directly. Indeed, the prospect of a direct confrontation with one's unchanging world may feed into a feeling of utter futility. Nevertheless, interpersonal processes might bridge the gulf by taking a series of smaller steps.

Certain more mundane experiences of impossibility are comparable in this respect. Take the example of trying to write a long and complicated philosophy paper. When it comes to writing that first word, the whole enterprise can seem utterly impossible. One remembers doing it many times before, that it often seemed impossible, and that it never was in the end. Yet, after one has sat there for a while, ineffectively willing oneself to begin, one instead distracts oneself from the task by reading film reviews of Alien: Covenant on the Internet, followed by episode synopses of Game of Thrones, while becoming increasingly anxious all the while. At that point, however, various tactics could be employed: “well, I can at least write the title”; "maybe I'll fill in some of the references"; "let’s just try to do that first paragraph”. Then, as one becomes progressively immersed in the process of writing, the initial sense of impossibility starts to dissipate (on a good day, at least). In fact, the writing can come to seem almost effortless - the keyboard rattles away as one coherent sentence after another appears on the screen. Interpersonal processes similarly have the potential to open up possibilities, by taking little steps rather than confronting the sense of impossibility head-on.

It is also important to emphasize that the experience of estrangement is seldom complete. It could be that a sense of potential connection with other people in general is diminished rather than absent, such that it can still be nurtured by some types of situation and interaction. Furthermore, it need not apply to all other people in the same way. One might feel cut off from other people in general, perhaps unable to trust a hostile social world, while continuing to depend on specific individuals, who are "different”. This is not to suggest that the sense of connection 
remains wholly intact in these cases, but that, where it is stronger to begin with, something of it is more likely to endure. While this can involve styles of relating to those people that eventually push them away, it can also sustain some sense of contingency, fluidity, hope:

"I feel very separate from people, fearing that if I talk about how I'm feeling they'll reject or disapprove of me. And yet, on the flipside of that, I can become very clingy and over-reliant on people, particularly my boyfriend, and fear that without him I'll somehow disappear.”

Of course, people often seek the advice and support of healthcare professionals as well. There is also much to be said about the roles played by prescribed medication (and its interpretation by self and others) in manipulating recalcitrant feelings of impossibility. However, for current purposes, I restrict myself to the theme of how experience is interpersonally regulated. Another important aspect of this is how people come to understand their depression and how others help them to do so. A prominent theme in most responses to the 2011 questionnaire study was that of self-understanding. Many respondents supplied lengthy accounts of what their depression consisted of, what caused it, and -in some instances- how they attempt to manage it. These accounts included detailed observations on the efficacy, inefficacy, and quite specific effects of various prescribed medications, descriptions of others' lack of understanding and, interestingly, remarks on how best to deal with this ignorance when engaging with others. ${ }^{7}$ Many respondents consulted a range of different resources in order to understand what was happening to them:

"I've tried everything to help me understand depression."

"I've looked on a lot of websites, I've read books about depression, I've seen various doctors. I feel that my understanding of depression now is quite good. I wanted to familiarise myself with it as much as possible so that I could find a way out. Towards the end of my recovery, while I was at university, I did several projects on depression, because it was something I was interested in, and to find out more about it.”

"I am constantly consulting internet sources in order to try and understand my depression and I sometimes chat on forums with other people going through the same things, in order to try and get

\footnotetext{
${ }^{7}$ Thanks to Gail Hornstein for first pointing out to me that the testimonies we collected described a range of sophisticated self-regulation strategies, even though I had not asked participants about this.
} 
a better understanding. I have also read different books regarding depression and have spoken in some depth about it with my general practitioner, care coordinator and counsellor.”

This kind of self-understanding might be sought while depressed, while recovering, and/or afterwards, feeding into how subsequent periods of depression are interpreted and regulated. For instance, it often includes specific causal hypotheses, of a kind that may aid self-regulation at one or another stage:

"For many of my depressive episodes I can pinpoint a trigger."

"My depression was a result of an undiagnosed anxiety disorder. When my anxiety disorder gets a bit out of hand, I get depressed. The anxiety disorder, my psychiatrist and I think, is a combination of genetic factors (my grandmother and cousins also have anxiety problems), an imbalance of serotonin and a personality trait. I will always be anxious and I will always get low quite easily, that's unavoidable. But I don't have to let it control my life.”

An ability to regulate experience through explicit understanding of it is closely associated with an ability to sustain some sense of connection with certain people. It is partly through trusted others that one constructs a narrative around one's depression, where they might include partners, friends, professionals, or support groups, and where interaction can take different forms, such as face-to-face conversation or interacting via the Internet. In addition, selfunderstanding often involves reading and discussing relevant bodies of literature, some of which one identifies with and some of which one does not. Again, which literature one consults and what one endorses depends in part on who one trusts - which individuals, groups, and authority figures:

"My partner has a degree in Psychology, specializing in depression, so he helped me to understand what was happening to me. But interestingly, he did not spot the signs of my depression, it is only in hindsight that he says I was a 'textbook case'.”

"Now that I'm starting to feel better again I'm more open to the idea that people are separate from me and so not always a mirror for who I am and how I'm feeling. That is, however, the result of therapy, I couldn't have come to that conclusion alone and I think I'll always have a tendency to rely on those around me for my self-image......I've seen GPs, several psychologists. I talked to 
friends more during my first episode....but in recent years that hasn't felt helpful - I didn't feel like I could be honest without incurring judgement. I went on a course about mindfulness, which was enormously helpful. Psychologists have shed some light on the causes of my difficulties, but mindfulness has helped me learned to cope with them. I used to steer clear of books, but my latest psychologist has recommended several that have been useful, to do with parenting, self-esteem, compassion etc."

“What haven't I tried! I have spoken to numerous GPs, consulted books, joined support groups online and read information about it - I have spoken to a counsellor and sought help. I have read self-help and medical books and magazines.”

It may well be that one can undermine or circumvent -to some degree- a felt sense of certainty and inescapability through intellectual insight. Consider the following passage:

"I had a lot of good friends that helped me through my depression and contributed to my recovery. But I also came to the point where I realised I was really going to have to work to get out of depression. It took so much work and energy that I barely had, but I do believe it is entirely possible to recover from depression. Once I started having a few good days I would tell myself 'look, you've had a good day before. You'll get it again' and I kept going. The depression tricks you into thinking you'll be this way for life and that anyone else who has recovered is just an exception. I thought that was the case for me, but having almost recovered I can see that it is entirely possible to be free from it."

Here, there is the acknowledgement that, while it seems to me as though $x$ is absolutely impossible, while I cannot even imagine a situation in which $x$ is the case for, I have to remember that I am being tricked and to act accordingly, however hard this might be.

To summarize, a consistent theme of most first-person accounts of depression is that people in general do not understand one's experience, cannot understand it, do not try to understand it, frown upon it, or simply do not care. This contributes to the pervasive feeling of isolation and inescapability that is so central to the "world" of depression. Existential feeling in depression is thus inseparable from a way of experiencing and relating (or, rather, not relating) to other people. These forms of experience, I have argued, pose a particular challenge to affectregulation, given that they do not incorporate a more usual sense of their own contingency. Even so, most of them remain, to some extent at least, porous to interpersonal influence. The quest for 
self-understanding, itself reliant on sustaining some degree of connection with certain other people, opens up further options. Phenomenologically accessible self-regulation processes can involve circumventing a sense that $x$ is impossible by taking smaller steps that need not involve working explicitly or directly towards the actualization $x$, something that includes varying degrees and kinds of insight.

It can be added that the case of “depression” serves to exemplify a point that applies to psychiatric illness more generally: disturbances of interpersonal experience are inseparable from disturbances of self, world, body, agency, and time (Ratcliffe, 2017). Hence there is the further task of distinguishing various different kinds of estrangement from other people, showing how these are associated with different disturbances of wider experience, thought, and activity, and addressing how a phenomenological understanding of these differences should relate to classificatory, diagnostic, and treatment practices.

Acknowledgements: Thanks to participants in the workshop 'Self-Management in Psychiatry' (Nijmegen, 2017) and to two anonymous referees for helpful comments on an earlier version of this paper.

\section{References}

American Psychiatric Association. 2013. Diagnostic and Statistical Manual of Mental Disorders (Fifth Edition). Arlington, VA: American Psychiatric Association.

Bayliss, A.P., Frischen, A., Fenske, M.J. and Tipper, S.P. 2007. Affective Evaluations of Objects are influenced by Observed Gaze Direction and Emotional Expression. Cognition 104: 644-653.

Becchio, C., Bertone, C. and Castiello, U. 2008. How the Gaze of Others influences Object Processing. Trends in Cognitive Sciences 12: 254-258.

Brampton, S. 2008. Shoot the Damn Dog: A Memoir of Depression. London: Bloomsbury.

Burnard, P. 2006. Sisyphus Happy: the Experience of Depression. Journal of Psychiatric and Mental Health Nursing 13: 242-6.

Colombetti, G. and Krueger, J. 2015. Scaffoldings of the Affective Mind. Philosophical Psychology 28: 1157-1176.

Diamond, L.M. and Aspinwall, L.G. 2003. Emotion Regulation across the Life Span: An Integrative Perspective Emphasizing Self-Regulation, Positive Affect, and Dyadic Processes. Motivation \& Emotion 27: 125-156.

Gross, J.J. 1999. Emotion Regulation: Past, Present, Future. Cognition and Emotion 13: 551-573. 
Gross, J.J. 2001. Emotion Regulation in Adulthood: Timing is Everything. Current Directions in Psychological Science 10: 214-219.

Leder, D. 1990. The Absent Body. Chicago: University of Chicago Press.

Løgstrup, K. E. 1956/1997. The Ethical Demand. Notre Dame: University of Notre Dame Press.

Minkowski, E. 1970. Lived Time: Phenomenological and Psychopathological Studies (Trans. Metzel, N.).

Evanston: Northwestern University Press.

Parnas, J., Møller, P., Kircher, T., Thalbitzer, J, Jansson, L. Handest, P. And Zahavi, D. 2005. EASE:

Examination of Anomalous Self-Experience. Psychopathology 38: 236-258.

Ratcliffe, M. 2005. The Feeling of Being. Journal of Consciousness Studies 12 (8-10): 43-60.

Ratcliffe, M. 2008. Feelings of Being: Phenomenology, Psychiatry and the Sense of Reality. Oxford: Oxford University Press.

Ratcliffe, M. 2015. Experiences of Depression: A Study in Phenomenology. Oxford: Oxford University Press.

Ratcliffe, M. 2017. Real Hallucinations: Psychiatric Illness, Intentionality, and the Interpersonal World. Cambridge MA: MIT Press.

Sebanz, N., Bekkering, H., and Knoblich, G. 2006. Joint Action: Bodies and Minds Moving Together. Trends in Cognitive Sciences 10: 70-76.

Sebanz, N. and Knoblich, G. 2009. Prediction in Joint Action: What, When, and Where. Topics in Cognitive Science 1: 353-367.

Shaw, F. 1997. Out of Me: The Story of a Postnatal Breakdown. London: Penguin.

Steinke, D. 2001. Poodle Bed. In Casey, N. ed. Unholy Ghost: Writers on Depression. New York: William Morrow: 60-66.

Stephan, A. 2012. Emotions, Existential Feelings, and their Regulation. Emotion Review 4:157-162. Varga, S. and Krueger, J. 2013. Background Emotions, Proximity and Distributed Emotion Regulation. Review of Philosophy and Psychology 4: 271-292.

Wolpert, L. 1999. Malignant Sadness: The Anatomy of Depression. London: Faber \& Faber.

World Health Organization 1992. The ICD-10 Classification of Mental and Behavioural Disorders:

Clinical Descriptions and Diagnostic Guidelines. Geneva: World Health Organization.

Zahavi, D. 2014. Self and Other: Exploring Subjectivity, Empathy, and Shame. Oxford: Oxford University Press. 